\title{
Some aspects of the metastatic process*
}

\author{
RL CARTER \\ From the Haddow Laboratories, Royal Marsden Hospital and Institute of Cancer Research, Sutton, Surrey
}

The ability to metastasise can reasonably be regarded as the single most important characteristic of the vast majority of malignant tumours. It is also the least understood. Purely descriptive accounts of some of the most critical phases of the metastatic process are still Jacking, and knowledge of the underlying mechanisms is rudimentary. Some advances are, however, being made and this review is concerned with work reported (for the most part) in the last decade which pertains to the two major metastatic pathways - lymphatic and haematogenous spread. The emphasis is on human studies but experimental data are included wherever necessary.

\section{Spread of tumour in the lymphatic system}

The lymphatics form the major route of dissemination for carcinomas and for many melanomas, neuroblastomas and malignant teratomas. Lymphborne metastases from sarcomas are uncommon but are most likely to be encountered in alveolar and embryonal rhabdomyosarcomas, synoviosarcomas and epithelioid sarcomas. ${ }^{1}$

PENETRATION INTO THE LYMPHATIC SYSTEM Primary tumours do not contain lymphatic vessels and the main points of entry of malignant cells into the lymphatic system are lymph capillaries near the growing edge of the neoplasm. The microanatomical location and the density of lymphatics vary considerably in different tissues and are important determinants in the eventual incidence and distribution of regional lymph node metastases. Small lymph vessels resemble blood capillaries in their histological structure, consisting of endothelial cells linked by various types of interendothelial junctions and bounded externally by a basement membrane which is frequently discontinuous. Lymphatics from different parts of the body vary in the numbers and organisation of interendothelial junctions and the

\footnotetext{
*An expanded version of a lecture given at the Armed Forces Institute of Pathology, Washington DC on June 16, 1981.

Accepted for publication 29 June 1982
}

arrangements of the basement membrane ${ }^{2}$; regional differences of this kind may in part determine the ease with which the lymphatic system is invaded at certain anatomical sites.

The process whereby tumour cells penetrate local lymphatic vessels is ill-documented. The scanty information available is based on experimental studies with various types of tumour cells inoculated into the footpads of rats. ${ }^{34}$ Serial examination of tissues in the electron microscope indicates that the injected tumour cells first align themselves along the lymphatic channels. They then appear to protrude cytoplasmic processes between endothelial cells and migrate through interendothelial junctions, either as single cells or as small clumps. Damage to contiguous endothelium and perivascular collagen fibres is usually minimal or absent. Lymphatics in the rat footpad appear to be almost devoid of basement membrane, and the endothelium provides the sole (and manifestly ineffective) barrier to be traversed by invading tumour. The processes whereby neoplastic cells breach the endothelial layer are unknown, but possible factors include mechanical pressure exerted by motile tumour cells and the local release of substances which cause endothelial retraction or inflict minute lesions on or near the junctional complexes.

Once tumour cells, singly or in clumps, have crossed the lymphatic wall, they enter a low-pressure flow system in which circulation is maintained by a combination of intrinsic contractions of the lymphatic walls and extra-lymphatic pressure exerted by the movements of local muscles and transmitted arterial pulsations. $^{5}$ Normal lymph contains little or no fibrinogen and platelets which, in the blood vascular system, play an important part in the arrest of circulating tumour cells and their subsequent escape into the extravascular compartment. Intralymphatic tumour is a common finding in surgical and necropsy material, usually seen as small clumps of cells lying free or occasionally still attached to the endothelial surface. Long segments of lymphatic vessels may be distended with growth which can sometimes be identified macroscopically. Intralymphatic tumour is 
difficult to recognise in poorly fixed, densely fibrous tissues where the lymphatic endothelium has been shed and the stroma has retracted to form small artefactual spaces round clumps of infiltrating tumour. Although important mainly as an indication of possible spread to regional lymph nodes, intralymphatic tumour without detectable nodal metastases is itself a notable finding for tumours at certain sites. It has, for example, been reported that patients with breast cancer with tumour cell emboli within intramammary lymphatics but without spread to axillary lymph nodes show an increased risk of developing visceral metastases. ${ }^{6}$

\section{RETENTION IN REGIONAL LYMPH NODES}

Disseminating tumour, carried in afferent lymph as single cells or small emboli, is initially trapped in the sinus system of the draining lymph nodes, the complex arrangement of which is strikingly revealed in low-power scanning electron micrographs. ${ }^{78}$ The retention of tumour cells in the sinus system has been confirmed in experimental studies in which neoplastic cells, sometimes labelled with radioisotope, are injected directly into afferent lymphatic vessels and their distribution followed for several days. ${ }^{8}$ There is, however, evidence from some investigations that tumour cells injected into local lymphatics may quickly traverse the regional lymph nodes. ${ }^{910}$ The efficiency (or otherwise) of the barrier function of lymph nodes remains unclear, and many aspects of the retention process are speculative. ${ }^{11}$

INTRANODAL TUMOUR: THE EARLY PHASES Various events ensue once tumour cells are retained in the local nodes - cell destruction, cell dormancy, and establishment and growth. The first two contingencies are scantily documented in experimental animals only, ${ }^{1}$ and the need for more detailed quantitative studies is obvious. The local conditions necessary for the establishment of a growing focus of tumour cells in a lymph node are obscure. Acquisition of an adequate blood supply is one critical requirement, and the normal lymph nodes have a well developed dual vasculature through hilar vessels and transcapsular anastomoses. The vasculature is adaptable and is rapidly augmented during, for example, the course of an immune response. Most nodal metastases appear to be adequately vascularised and may grow to form large masses several centimetres in diameter. Necrosis is, however, a characteristic feature of rapidly proliferating nodal deposits (from tumours such as melanomas, small cell anaplastic carcinomas of the bronchus, neuroblastomas, anaplastic seminomas and malignant teratomas) and of malignant lymphomas. Haemorrhage and necrosis may result from invasion of intranodal blood vessels by growing tumour. High endothelial-lined vessels are a characteristic (and diagnostically useful) feature of nodes infiltrated by $T$ cell lymphomas, perhaps reflecting the production of $T$ cell-associated angiogenesis factors. ${ }^{88}$ Growth of nodal metastases is usually continuous with progressive replacement of the pulp. The growth pattern and degree of cellular differentiation of the primary neoplasm tends to be reproduced, though the development of metastases which are less differentiated than the primary growth is a familiar finding. Undifferentiated nodal metastases may present diagnostic problems, particularly if the primary tumour is occult, and immunoperoxidase and other modern histological techniques are valuable. ${ }^{12}$ Large nodal deposits are often still confined within an intact capsule. Transcapsular spread is, however, a common feature for some tumours such as malignant melanomas and squamous carcinomas of the head and neck; capsular infiltration in partially involved lymph nodes is frequently seen, reinforcing scepticism for the simple notion that the capsule is disrupted by increased intranodal pressure.

\section{INTRANODAL TUMOUR: SOME LATE EFFECTS}

As the lymph node is replaced by metastatic tumour, lymph perfusion through the pulp will diminish and tumour cells will be carried to other nodes in the same or contiguous anatomical groups. Various complications of intranodal lymphatic obstruction will ensue. Retrograde lymph flow can cause tumour cells to be carried to more distant parts of the lymphoid system where they give rise to anatomically anomalous deposits of metastatic tumour. Retrograde flow is also responsible for spread of tumour cells, still within lymphatics, to sites outside the conventionally defined lymphoid system. Necropsy studies of disseminated breast cancer have shown widespread lymphangitis carcinomatosa in the visceral and parietal pleura and lung parenchyma. ${ }^{13}$ Similar lymphatic spread may occur in the liver. Local obstruction of lymphatic vessels will lead to oedema and, in the case of diaphragmatic lymphatics, to ascites - though the relative importance here of decreased lymphatic absorption and increased production of intraperitoneal fluid is uncertain. ${ }^{14} 15$ Tumour cells may disseminate from lymph nodes into the vascular system at several points. They include small intranodal vessels; extranodal vessels invaded by metastatic tumour which has breached the nodal capsule; lymphaticovenous communications opening up in the involved lymph node; and the thoracic duct. Such spread is usually regarded as a late event, occurring when most or all of a lymph node is replaced by metastatic tumour. The basis for this assumption is unclear, and there are no a priori reasons why 
intranodal tumour cells should not disseminate further in the blood stream at an earlier phase.

The localisation of nodal metastases is largely determined by the local anatomy, though anomalies sometimes arise. Normal pathways of lymphatic drainage may be modified by previous radiotherapy and major surgery. Retrograde spread of intralymphatic tumour has already been noted. Certain aspects of the basic anatomy at some sites are still unclear, and the continuing discussion as to whether each breast quadrant does or does not have a consistent and specific pattern of lymph drainage provides one example. ${ }^{16}$ The more important question of predicting whether nodal metastases will develop - as opposed to forecasting their anatomical distribution - is complex and speculative, and falls outside the scope of this short account.

\section{Spread of tumour in the vascular system}

Sarcomas disseminate predominantly by the blood stream, and melanomas, neuroblastomas and malignant teratomas spread almost equally in the blood and lymphatic systems. Haemic dissemination is an important and often underestimated metastatic route for carcinomas, ${ }^{17}$ even though lymphatic spread predominates in many instances.

\section{PENETRATION INTO THE}

BLOOD VASCULAR SYSTEM

Malignant cells enter the circulation by invading blood vessels situated either within the substance of the main tumour mass or near its advancing edge; they may also gain access indirectly through the lymphatic system - see earlier. The vasculature of tumours originates from pre-existing vessels in the tissue of origin and from newly formed vessels derived from them. The stimuli for angioneogenesis within tumours are unclear, but they are likely to stem from host sources (especially local lymphocytes) as well as from neoplastic cells themselves. ${ }^{18}{ }^{19}$ Such vessels are extensive and often imperfectly formed with irregular lumina, discontinuous and sometimes abnormal endothelium, defective basement membrane and (in larger vessels) scanty or absent perivascular connective tissues. Sarcomas often contain large blood-filled channels wholly or partly lined by malignant cells which can shed direct into the blood. Vascular endothelium in experimental tumours is capable of intense proliferative activity ${ }^{20}$ and, in clinical material, endothelial hyperplasia is a distinctive feature of high grade astrocytomas and (to a lesser extent) other primary intracranial neoplasms. Similar vessels are seen in some brain metastases, and they have also been described in the very rare extracranial metastases from gliomas in sites such as cervical lymph nodes. ${ }^{21}$ Despite the extensive vasculature, the rapid endothelial turnover and the overall high perfusion rate in many tumours, regional perfusion with them is frequently defective. Many of the abnormal vessels are excessively permeable and the interstitial compartment in most tumours is large. ${ }^{22}$ The accumulation of pericellular fluid is enhanced by the absence of any intrinsic lymphatic drainage. Regions of necrosis within a tumour, and the accumulation of oedema fluid and fibrin at its edges, are at least in part explained by such circumstances. Necrosis is often marked in rapidly proliferating tumours with a large cell loss fraction, and such tumours, which are sometimes very small, have a notably high metastatic rate. Examples include small cell anaplastic carcinomas of the bronchus, melanomas, malignant teratomas and choriocarcinomas. There is some experimental evidence that local necrosis favours the detachment of cells from the growing tumour mass. ${ }^{23}$

Normal blood vessels at or near the edge of the tumour are fewer and less readily penetrated by invading cells, but they represent the major route for haemic dissemination. Capillaries and small veins are the principal sites of entry. The process whereby tumour cells cross the vessel walls is unknown. Larger vessels, occluded by neoplastic cells and thrombi, are usually easy to rezognise but smaller vessels lacking organised connective tissue coats are more problematic, particularly in dense stroma. Immunohistochemical stains for Factor VIIIassociated antigen in normal endothelium are helpful in suitably fixed tissues. ${ }^{24}$ Invasion of large, wellperfused, thick-walled veins with contractile muscle coats appears to be particularly hazardous. ${ }^{17}$ An example is provided by recent work on venous invasion by carcinoma of the rectum ${ }^{25} 26$ in which close correlation was demonstrated between infiltration of extramural, thick-walled veins and the incidence of hepatic metastases. Local arteries are rarely invaded by neoplastic cells. Infiltrating tumour characteristically encircles them but appears to stop a short distance beyond the outer border of the adventitia. The thickness or composition of the arterial wall cannot be implicated, and there is some experimental evidence which suggests that transmitted pulse pressure may be responsible. ${ }^{27}$

\section{CIRCULATING TUMOUR CELLS}

Tumour cells free in the circulation have been extensively studied, but to little ultimate benefit. ${ }^{28}$ Most of the work is rendered suspect by inadequate attention to technical details (number and size of blood samples, their timing, sites of venepuncture, choice and methods of cell concentration) and to the criteria for identification of malignant cells in 
cytological preparations. Such investigations are inevitably - wholly qualitative and certain simple questions are left unanswered: What proportion of circulating cells is alive? How many cells are still able to divide? How many cells lack the vital capacity to stick to vascular endothelium? The demonstration of neoplastic cells in leucocyte concentrates appears to have little or no prognostic implication for any tumour at any site so far studied.

Some quantitative data on the release of cells into the circulation from transplanted tumours are available from studies in mice ${ }^{29}$ and rats $^{30}$ and extensive work has been done on the fate of tumour cells injected intravenously in experimental animals. " 31 Such manoeuvres are convenient but artificial, in that they by-pass the essential phase of vascular invasion, and extrapolation of results to the metastatic process as it really exists is often questionable.

\section{ARREST OF CIRCULATING TUMOUR CELLS}

The morphological changes which ensue when tumour cells are arrested in the circulation were meticulously described in both clinical and experimental material in the early part of this century. In brief, tumour cell emboli in small vessels of the lungs, liver and other tissues stick to vascular endothelium where they are covered by fresh thrombus. Some tumour cells grow progessively, filling the lumen and eventually escaping out into the extravascular compartment. Others remain entrapped in thrombi which are endothelialised and become organised with subsequent hyalinisation and fibrosis. Organising thrombi occasionally contain a few well-preserved tumour cells, some of them even seen in mitosis. These morphological events, based on sequential but inevitably static observations, were confirmed by Sumner Wood in his classical studies of tumour cells injected proximal to ear chambers implanted in rabbits. ${ }^{32}$ The process is one of great complexity, and several aspects remain controversial. Examples include the interplay of mechanical, haemodynamic and electrostatic forces in the initial impact of tumour cells on the endothelial surface; the processes whereby contact becomes attachment; the initiation of local thrombus formation and (by implication) the role of anticoagulants and fibrinolysins; and the processes whereby tumour cells extravasate into the surrounding tissues. These topics are discussed elsewhere ${ }^{1133}$ but one general point needs to be stressed. Morphological studies in the light microscope, ultrastructural investigations and the direct cinemicrographic observations made in the living animal all emphasise that tumour cells sticking to vascular endothelium do not invariably complete the full sequence of vascular destruction and extra- vasation. Many tumour cells will die within the thrombus, and others will be swept back into the circulation when the surrounding platelet-fibrin aggregates dissolve. No quantitative data are available, but it is reasonable to suppose that only a minority of arrested tumour cells will succeed in escaping into the interstitial compartment metastasis, for all its lethal consequences, is in biological terms a distinctly inefficient process. ${ }^{3435}$

\section{Use of in vitro models}

Some of the mechanisms whereby tumour cells escape from blood vessels have recently been investigated with in vitro systems. Bovine aortic endothelium, which also synthesises basement membrane components, provides a useful substrate; and there is growing knowledge of the biochemistry of basement membrane components, notably the adhesive glycoproteins (such as laminin and fibronectin) and type IV collagen. A summary of some recent work is given in Table 1 . The results are interesting but certain limitations are immediately apparent. The tumour cells so far tested are somewhat limited in variety and are derived from cell lines. The dynamic interactions between tumour cells and vascular endothelium are virtually eliminated. Three-dimensional vascular structures are reduced to a simplified two-dimensional planar surface or a pure chemical substrate. Other components, notably local platelet-fibrin aggregates, are absent. Recent experiments with artificial blood vessels built up from bovine aortic endothelium and multilayers of rat smooth muscle provide some illuminating results. ${ }^{46}$ Destruction of subendothelial smooth muscle by human fibrosarcoma cell lines appears to be retarded in this system if intact endothelium is present - a finding which would be quite inapparent in a simpler (but arguably less representative) test system. Considerable caution is clearly necessary in extrapolating from static in vitro models to the turbulent situation that obtains in vivo.

EXTRAVASCULAR TUMOUR

Early events after tumour cells have crossed into the extravascular space are particularly ill-understood. Many cells are likely to die for purely metabolic reasons while others may be destroyed by host cells which initially will be at a numerical advantage. Some extravascular tumour cells will probably enter local lymphatics. ${ }^{47}$ Establishment and growth beyond a critical surface area/volume relationship is likely to be determined by the acquisition of a fibrovascular stroma. Wood's cinemicrographic studies showed that a developing nidus of extravascular tumour in the rabbit ear was well vascularised within $36 \mathrm{~h}$. Micrometastases lacking an adequate blood supply are 
Table 1 Aspects of extravasation of tumour cells studied in in vitro systems

(a) Penetration of endothelium

1 Loose attachment of tumour cells to endothelium

2 Retraction of endothelium with exposure of basement membrane

3 Spread of tumour cells beneath endothelial monolayers - Complete process $1 \rightarrow 3$ demonstrated with tumour cells derived from cell lines from human, rat and mouse tumours.

- Incomplete process $1 \rightarrow 2$ demonstrated with various normal control cells EXCEPT for human polymorphs and monocytes.

- Capacity to attach to endothelial monolayers in vitro varies with different tumour types, possibly related to metastatic potential

(b) Adhesion to basement membrane

Tight attachment of tumour cells to adhesive glycoproteins such as fibronectin, laminin and (?) type IV collagen (codistributed with laminin).

- Demonstrable by immunofluoresence and immunoperoxidase methods

- Capacity to attach to basement membrane-derived

glycoproteins in vitro varies with different tumours

(? carcinoma cells binding to laminin. sarcoma cells to laminin and fibronectin).

(c) Destruction of basement membrane

Measured by degradation of whole basement membrane or purified basement membrane-derived type IV collagen. Destructive activity is:

- substrate specific

- associated with tumour cells and their supernatant culture media

- probably related to metastatic potential

Data based on references $36-45$

likely to remain dormant; but the whole question of tumour dormancy remains obscure and the relative contributions of neovascularisation, tumour cell kinetics and host inflammatory and immune responses are almost totally speculative.

Once a nidus of tumour cells starts to expand it will infiltrate surrounding tissues in the same way as a primary neoplasm. The topic of tumour invasion falls outside the scope of this review, but one point should be noted - the growing evidence that host elements play an important role in the invasive process. In soft tissues, for example, it is local polymorphs, macrophages and fibroblasts near the tumour's growing edge which elaborate potent proteases. Comparable activity in the tumour cells themselves may be less or even absent ${ }^{48-50}$ though the operation of functional interactions between neoplastic cells and the tumourassociated stromal components is virtually certain. A comparable situation is seen when tumour cells are invading cortical bone: most bone destruction appears to be mediated by osteoclasts which are activated locally by both the tumour and the adjacent stroma. ${ }^{50-53}$

Human tumours implanted as xenografts in immune-depressed animals are unsatisfactory models for studying local growth patterns. Irrespective of their previous clinical behaviour, such tumours form slowly growing lesions enclosed in fibrous tissue.
Neoplastic infiltration of local tissues, and metastasis, are both exceptional events. ${ }^{54}$

The later stages of metastatic development need no detailed comment. Growth is usually progresive and, in some instances, doubling times have been shown to be greater than those of the primary tumour by a factor of 1.5 to $2 .{ }^{55}$ Spontaneous arrest and regression of metastases are exceptionally rare " and the underlying mechanisms are unknown. Most established metastases resemble their parent tumour in histological structure though, as in lymph nodes, marked dedifferentiation may lead to diagnostic problems for the pathologist. Identification of small lesions, especially in the liver and bone marrow, is aided by immunoperoxidase techniques and the widely distributed epithelium membrane antigen (EMA) is proving particularly useful. ${ }^{1256}$

\section{Localisation of metastases}

The distribution of lymph-borne metastases was discussed earlier and this final section is concerned with the localisation of blood-borne tumour. Some of the factors implicated are summarised in Table 2.

The large pulmonary and hepatic vascular beds form the first and quantitatively most important filters for trapping circulating tumour cells, and the lungs and liver are the two commonest sites of haemic metastases. A third set of primary filters is probably provided by the terminations of Batson's paravertebral venous plexuses in parts of the axial skeleton. ${ }^{57}$ The importance of these plexuses as a metastatic pathway is disputed ${ }^{17}$ and the situation is complicated as blood-borne tumour cells may reach the skeleton by at least two routes - directly through the paravertebral venous plexuses and also by the systemic circulation through the peripherally directed branches of the nutrient arteries. Tumours also invade contiguous bone by direct extension. Bross and his colleagues ${ }^{5859}$ have proposed that the lungs and liver act as "key generalising sites" from which subsequent metastases are generated. Their data are

\section{Table 2 Localisation of blood-borne metastases}

(a) Host factors
Haemodynamics
Blood volume, blood flow, transit times, regional variations
within organs
Organisation of vasculature
Gross aspects, histology, ultrastructure, functional aspects
Normal tissue milieu
Local and systemic factors
Trauma, inflammation, irradiation, immune status
(b) Tumour cells
Single or embolic clumps
Quantitative aspects ("dose/time" relationship)
Surface properties including possible membrane determinants
for organ specificity
? Metastatic heterogeneity of genotypic subpopulations


now extensive and are derived from large numbers of tumours arising at many sites, but the limitations of the hypothesis need to be borne in mind. The information is based on necropsy findings and thus reflects advanced, often long-standing, end-stage disease which has been previously treated. Lymphatic dissemination is not included and it was noted earlier that parenchymal organs such as the lungs and liver can be extensively infiltrated by lymph-borne tumour from a distant primary in the form of lymphangitis carcinomatosa. It is self-evident that a proportion of tumour calls initially trapped in the primary capillary filters can escape. In the early stages, some cells may squeeze through capillary lumina and enter the systemic circulation while others traverse vascular shunts. Later, tumour cells may be released from established foci in these regions; Willis ${ }^{17}$ has stressed that such deposits may be minute.

The non-random distribution of systemic metastases outside the lungs, liver and parts of the axial skeleton is one of the oldest observations of tumour pathology. It still remains true, but certain features may be noted. Detailed necropsies on some patients with tumours such as carcinoma of the breast, melanoma and some soft tissue sarcomas, show that metastases can develop at almost any site. Metastases in the spleen are not the rarities they are sometimes made out to be. ${ }^{17}$ Secondary deposits in the adrenals are probably drawn from a wider spectrum of primary tumours than is often supposed. ${ }^{60}$ Furthermore, metastatic patterns from any one tumour type are not immutable. Necropsy studies are now showing that squamous carcinomas of the head and neck quite frequently metastasise to distant sites, ${ }^{61}$ that osteosarcomas may also spread to extrapulmonary tissues such as lymph nodes, abdominal viscera and other parts of the skeleton ${ }^{62}$ and that the distribution of metastases from breast cancer may be changing as a result of treatment. ${ }^{63}$ Some of the factors that are implicated in the localisation of blood-borne metastases have been summarised in Table 2 . The traditionally disparate elements of the "haemodynamic" and "soil and seed" theories of metastatic localisation, associated with James Ewing and Stephen Paget, have been deliberately merged as the distinction seems futile.

Apart from the lungs and liver, no wholly consistent association has yet been established between the organ distribution of systemic bloodborne metastases and regional haemodynamic characteristics such as blood volume, blood flow and transit times within a specific organ. ${ }^{64}$ The methods available may not be sufficiently accurate and the importance of more refined haemodynamic studies, particularly with repect to regional variations in blood flow within a viscus, remains to be examined. Local variations in vascular structure and function have received little attention. Earlier workers ${ }^{65}$ suggested that thîck-walled arterioles in tissues such as the spleen and skeletal muscle might provide a mechanical barrier preventing the egress of circulating tumour cells, but other more subtle features may operate as well. The interaction of local haemodynamic factors and local vascular organisation is well illustrated in the bone marrow. The sinusoidal system in red marrow has a large blood volume and slow perfusion with a tendency to intermittent reflux flow, and the spaces are lined by a discontinuous, often attenuated endothelial layer which appears to lack tight junctions. ${ }^{66-68}$ Such conditions are well suited to ensure (under physiological conditions) the unimpeded passage of mature blood cells from extravascular haematopoietic foci in the marrow into sinusoidal blood. These same conditions will, however, be no less favourable for the reverse passage of tumour cells from the sinus capillaries and their subsequent colonisation of the extravascular tissue spaces. The normal tissue milieu may be modified equally by local and general systemic factors affecting the whole body such as inflammation, trauma, irradiation and immune status. There is experimental evidence, for example, that immune status will modify the retention, distribution and growth of disseminated malignant cells. ${ }^{69-71}$ The complexity of the situation is illustrated by recent experience with athymic nude mice which are almost refractory to developing lung deposits from allogeneic or xenogeneic tumour cells even when injected directly into the venous system. ${ }^{72}$

The extent to which the distribution of metastases is determined by tumour cells themselves is unknown. Factors such as the rate of release of cells from the primary lesions, and their presence in the circulation as single cells or clumps, are likely to be important - but the fundamental question relates to whether certain intrinsic properties of the tumour cells determine their tendency to seed "preferentially" in certain sites or, indeed, to metastasise at all. The evidence available is based on experimental studies, and the implications for man are unclear. A detailed appraisal of this work falls outside the scope of the present review, but two of the principal strands of evidence may be very briefly summarised as follows:

1 A series of transplantable mammary carcinomas in rats has been established by $\mathrm{Kim}^{73}$ with consistent and distinctive metastatic patterns. Blood-borne and lymphborne metastases may develop and the target sites include the skeleton in two instances. Investigations suggest that the metastatic variants have unstable plasma membrane structures with abnormal shedding of glycoproteins, glyocolipid 
antigens, surface marker enzymes, glycosyltransferases and other enzymes. Such abnormalities may lead to alterations in immunogenicity, membrane permeability and to cell locomotion; but the extent to which such features may determine the differential localisation of metastatic tumour cells in target organs remains unclear.

2 Extensive studies have been made by Fidler and his colleagues on the metastatic potential and organ selectivity of transplantable tumours in mice, notably the B16 melanoma. ${ }^{74-76}$ Sublines of the tumours have been established with an enhanced capacity to grow not only in the lungs - the usual site of metastasis for the B16 melanoma - but also in the brain, ovary and liver. ${ }^{77-79}$ following intravascular injection of cells at an appropriate site. The isolation by cloning of high and low-metastasising strains of cells provides unequivocal evidence in favour of specific metastatic subpopulations. There are difficulties in the appraisal of experiments in which tumour cells are injected directly into the vascular system, and it is essential to confirm the behaviour of these seemingly selective tumour cell lines by growing them as subcutaneous or intramuscular implants from which "natural" metastases may be generated. Evidence from such experiments is conflicting $;{ }^{3580} 81$ but the distinction between colonising and truly metastasising tumour cells which seems to be emerging illustrates the interpretative difficulties of this kind of modal system.

There is growing evidence that human tumours are heterogeneous with respect to features such as karyotypes and DNA content, the presence of hormone receptors, antigenic determinants and cell surface constituents, pigment synthesis, drug sensitivity, in vitro growth characteristics and growth as xenografts in immune-suppressed mice. ${ }^{\times 2-x i}$ Similar differences, albeit less clearly defined, have been described for some properties from primary and metastatic tumours in man. Whether such characteristics can be associated with specific genotypic sub-populations with an enhanced capacity to metastasise is wholly unknown, and the need to consider the probable operation of several different, non-exclusive metastatic mechanisms should require no special pleading. ${ }^{3+}$

\section{References}

' Enterline HT. Histopathology of sarcomas. Semin Oncol 1981; 8:133-.55.

2 Yoffey JM, Courtice FC. Lymphatics, lymph and the lymphomyeloid complex. London and New York: Academic Press, 1970.

${ }^{3}$ van de Velde C, Carr I. Lymphatic invasion and metastasis. Experientia 1977;33:837-43.

+ Carr I, Carr J, Dreher B. Lymphatic metastases of mammary adenocarcinoma. An experimental study in the rat with a brief review of the literature. Invasion Metastasis 1981;1:34-53.
${ }^{5}$ Hall JG. The flow of lymph. $N$ Engl J Med 1969;281:720-1.

- Nime FA, Rosen PP, Thaler HT, Ashikari R, Urban JT. Prognostic significance of tumor emboli in intramammary lymphatics in patients with mammary carcinoma. Am J Surg Pathol 1977;1:25-30.

' Luk SC, Hopajaroonsri MD, Simon GT. The architecture of the normal lymph node and hemolymph node. Lab lnvest 1973;29: 258-65.

* Wallace AC, Josephson RL, Hollenberg NK. Observations on lymph node metastases. In: Grundmann E, ed. Metastatic tumor growth. Stuttgart, New York: Gustav Fischer Verlag, 1980:83-99.

9 Fisher B, Fisher ER. Transmigration of lymph nodes by tumor cells. Science 1967;152:1397-8.

${ }^{10}$ Hewitt HB, Blake E. Quantitative studies of translymphnodal passage of tumour cells naturally disseminated from a nonimmunogenic murine squamous carcinoma. Br J Cancer 1975; 31:25-35.

"Carter RL. General pathology of the metastatic process. In: Baldwin RW, ed. Secondary spread of cancer. London, New York, San Francisco: Academic Press, 1978:1-52.

12 Sloane JP, Ormerod MG. Distribution of epithelial membrane antigen in normal and neoplastic tissues and its value in diagnostic tumor pathology. Cancer 1981;47:1786-95.

13 Thomas JM, Redding WH, Sloane JP. The spread of breast cancer: importance of the intrathoracic lymphatic route and its relevance to treatment. Br J Cancer 1979;40:540-7.

${ }^{14}$ Feldman GB, Knapp RC. Lymphatic drainage of the peritoneal cavity and its significance in ovarian cancer. Am J Obstet Gynecol 1974; :991-4.

is Fastaia J, Dumont AE. Pathogenesis of ascites in mice with peritoneal carcinomatosis. J Natl Cancer Inst 1976;56:547-50.

${ }^{16}$ Haagensen CD. Diseases of the breast. 2nd ed, revised. Philadelphia and London: WB Saunders, 1971.

17 Willis RA. The spread of tumours in the human body. 3rd ed. London: Butterworths, 1973.

${ }^{18}$ Folkman J. Tumor angiogenesis. In: Becker FF, ed. Cancer, A comprehensive treatise vol 3. New York and London: Plenum Press, 1975:355-88.

19 Gullino PM. Angiogenesis and neoplasia. N Engl J Med 1981; 305:884-5.

${ }^{20}$ Denekamp J. Endothelial cell proliferation as a novel approach to targeting tumour therapy. Br J Cancer 1982;45:136-9.

2 Russell DS. Rubinstein LJ. Pathology of tumours of the nervous system. 4th ed. London: Edward Arnold, 1977.

"- Gullino PM. Extracellular compartments of solid tumors. In: Becker FF, ed. Cancer, a comprehensive treatise. New York and London: Plenum Press, 1975:327-54.

${ }^{23}$ Weiss L. Tumor necrosis and cell detachment. Int J Cancer 1977; 20:87-92.

${ }^{24}$ Mukai K, Rosai J, Burgdorf WC. Localisation of factor VIIIrelated antigen in vascular endothelial cells using an immunoperoxidase method. Am J Surg Pathol 1980;4:273-6.

${ }^{25}$ Talbot JC, Ritchie S, Leighton MN, Hughes AO, Bussey HJR, Morson BC. The clinical significance of invasion of veins by rectal cancer. Br J Cancer 1980;67:439-42.

${ }^{26}$ Talbot IC, Ritchie S, Leighton M, Hughes AO, Bussey HJR, Morson BC. Invasion of veins by carcinoma of the rectum: method of detection, histological features and significance. Histopathology 1981;5:141-63.

${ }^{27}$ Shivas AA, Finlayson NDC. The resistance of arteries to tumour invasion. Br R Cancer 1965;19:486-9.

${ }^{28}$ Salsbury AJ. The significance of the circulating cancer cell. Cancer Treatment Rev 1975;2:55-72.

29 Liotta LA, Kleinerman J, Saidel GM. Quantitative relationships of intravascular tumor cells, tumor vessels, and pulmonary metastases following tumor implantation, Cancer Res 1974;34: 997-1004.

31) Butler TP, Gullino PM. Quantitation of cell shedding into efferent blood of mammary adenocarcinoma. Cancer Res 1975;35: 
$512-6$

${ }^{31}$ Fidler IJ. Metastasis: quantitative analyses of distribution and fate of tumor emboli labelled with ${ }^{125} 1-5$-iodo-2'-deoxyuridine. $J$ Natl Cancer Inst 1970;45:773-82.

${ }^{32}$ Wood S Jr. Pathogenesis of metastasis formation observed in vivo in the rabbit ear chamber. Arch Pathol 1958;66:550-68.

${ }^{33}$ Weiss L, ed. Fundamental aspects of metastasis. Amsterdam, Oxford: North-Holland, 1976.

${ }^{34}$ Weiss $\mathrm{L}$. Dynamic aspects of cancer cell populations in metastasis. Am J Pathol 1979;97:601-8.

${ }^{35}$ Weiss L, Mayhew E, Glaves Rapp D, Holmes JC. Metastatic inefficiency in mice bearing B16 melanomas. Br J Cancer 1982; 45:44-53.

${ }^{36}$ Liotta LA, Kleinerman J, Catanzaro P, Rynbrandt D. Degradation of basement membrane by murine tumor cells. $J$ Natl Cancer Inst 1977;58:1427-31.

${ }^{37}$ Liotta LA, Abe S, Robey PG, Martin GR. Preferential digestion of basement membrane collagen by an enzyme derived from a metastatic murine tumor. Proc Natl Acad Sci USA 1979;76: 2268-72.

${ }^{3 \times}$ Liotta LA, Tryggvason K, Garbisa S, Gehron Robey P, Murray JC. Interaction of metastatic tumor cells with basement membrane collagen. In: Grundmann E, ed. Metastatic tumor growth. Stuttgart, New York: Gustav Fischer Verlag, 1980; 21-30.

${ }^{39}$ Liotta LA, Tryggvason K, Garbisa S, Hart I, Foltz CM, Shafie S. Metastatic potential correlates with enzymatic degradation of basement membrane collagen. Nature 1980;284:67-8.

${ }^{40}$ Birdwell CR. Gospodarowicz D, Nicolson GL. Identification, localisation and role of fibronectin in cultured bovine endothelial cells. Proc Natl Acad Sci USA 1978;75:3273-7.

${ }^{41}$ Kramer RH, Nicolson GL. Interactions of tumor cells with vascular endothelial cell monolayers: a model for metastatic invasion. Proc Natl Acad Sci USA 1979;76:5704-8.

${ }^{42}$ Kramer RH, Gonzalez R, Nicolson GL. Metastatic tumour cells adhere preferentially to the extracellular matrix underlying vascular endothelial cells. Int J Cancer 1980;26:639-45.

${ }^{43}$ Vlodavsky I, Gospodarowicz D. Respective roles of laminin and fibronectin in adhesion of human carcinoma and sarcoma cells. Nature 1981;289:304-6.

44 Vlodavsky I, Lui GM, Gospodarowicz D. Morphological appearance, growth behaviour and migratory activity of human tumor cells maintained as extracellular matrix versus plastic. Cell 1980;19:607-16.

45 Murray JC, Liotta L, Rennard SI, Martin GR. Adhesion characteristics of murine metastatic and non-metastatic tumor cells in vitro. Cancer res 1980;40:347-51.

46 Jones PA, Neustein HB, Gonzales F, Bogenmann E. Invasion of an artificial blood vessel wall by human fibrosarcoma cells. Cancer Res 1981;41:4613-20.

${ }^{47}$ Hilgard P, Beyerle L, Hohage R. Hiemeyer V, Kubler M. The effect of heparin on the inital phase of metastasis formation. Eur J Cancer 1972;8:347-52.

${ }^{48}$ Graf M, Baici A, Strauli P. Histochemical localisation of cathepsin $\mathrm{B}$ at the invasion front of the rabbit V2 carcinoma. Lab Invest 1981;45:587-96.

49 Burman JF, Carter RL. Infiltration of soft tissues by squamous carcinomas of the head and neck. Submitted for publication.

${ }^{50}$ Carter RL. Morphological patterns of bone destruction by infiltrating tumours. In: Powles TJ, Bockman RS, Honn KV, Ramwell P, eds. Prostaglandins and cancer New York: Allan Liss, 1982:561-6.

${ }^{51}$ Galasko CSB. Mechanisms of bone destruction in the development of skeletal metastases. Nature 1976;263:507-8.

52 Carter RL, Pittam MR. Squamous carcinomas of the head and neck: some patterns of spread. J Roy Soc Med 1980;73:420-7.

${ }^{33}$ Tsao S-W, Burman JF, Easty DM, Easty GC, Carter RL. Some mechanisms of local bone destruction by squamous carcinomas of the head and neck. Br J Cancer 1981;43:392-401.

${ }^{54}$ Sharkey FE, Fogh J. Metastasis of human tumors in athymic nude mice. Int J Cancer 1979;24:733-8.

ss Tubiana M, Malaise EP. Growth rate and cell kinetics in human tumours: some prognostic and therapeutic implications. In: Symington T, Carter RL, eds. Scientific foundations of oncology London: Heinemann, 1980:126-36.

s6 Sloane JP, Ormerod MG, Imrie SF, Coombes RC. The use of antisera to epithelial membrane antigen in detecting micrometastases in histological sections. Br J Cancer 1980;42:392-8.

57 Drury RAB, Palmer PH, Higham WJ. Carcinomatous metastasis to the vertebral bodies. J Clin Pathol 1964;17:448-57.

${ }^{5 *}$ Bross IDJ, Blumenson IE. Metastatic sites that produce generalized cancer: identification and kinetics of generalizing sites. In: Weiss L, ed. Fundamental aspects of metastasis. NorthHolland Publishing Company, 1976:359-75.

${ }^{59}$ Bross IDJ. The biostatistical and biological basis for a cascade theory of human metastasis. In: Grundmann E, ed. Metastatic tumor growth. Stuttgart, New York: Gustav Fischer Verlag: 207-27.

${ }^{60}$ Symington T. Functional pathology of the human adrenal gland Edinburgh \& London: E and S Livingstone, 1969.

${ }^{61}$ Probert JC, Thompson RW, Bagshaw MA. Patterns of spread of distant metastases in head and neck cancer. Cancer 1974; 33:127-33.

62 Jeffree GM, Price CHG, Sissons HA. The metastatic patterns of osteosarcoma. Br J Cancer 1975;32:87-107.

${ }^{63}$ Amer MH. Chemotherapy and patterns of metastasis in breast cancer patients. J Surg Oncol 1982;19:101-5.

${ }^{64}$ Weiss L, Haydock K, Pickren JW, Lane WW. Organ vascularity and metastatic frequency. Am J Pathol 1980;101:101-14.

${ }^{65}$ Coman DR. Mechanisms responsible for the origin and distribution of bloodborne tumor metastases: a review. Cancer Res 1953;13:397-404.

${ }^{66}$ Johnston AD. Pathology of metastatic tumors in bone. Clin Orthoped 1970;73:8-32.

${ }^{67}$ Tavassoli M, Shaklai M. Absence of tight junctions in endothelium of marrow sinuses: possible significance for marrow cell egress. Br J Haematol 1979;41:303-307.

${ }^{68}$ Tavassoli M. The marrow-blood barrier. Br J Haematol 1979; 41:297-302.

${ }^{69}$ Weston BJ, Carter RL, Easty GC, Connell DI, Davies AJS. The growth and metastasis of an allografted lymphoma in normal, deprived and reconstituted mice. Int J Cancer 1974;14:176-85.

${ }^{70}$ Fidler IJ, Gersten DM, Riggs CW. Relationship of host immune status to tumor cell arrest, distribution and survival in experimental metastasis. Cancer 1977;40:46-55.

"Glaves D. Metastasis: reticuloendothelial system and organ retention of disseminated malignant cells. Int $J$ Cancer 1980;26:115-22.

${ }^{2}$ Hanna N, Fidler IJ. Expression of metastatic potential of allogeneic and xenogeneic neoplasms in young nude mice. Cancer Res 1981;41:438-44.

${ }^{73} \mathrm{Kim}$ U. Factors influencing metastasis of breast cancer. In: McGuire WL, ed. Breast cancer current topics. New York and London: Plenum Press, 1979:1-49.

74 Fidler IJ. Selection of successive tumour lines for metastasis. Nature New Biol 1973;242:148-9.

75 Fidler IJ. Tumor heterogeneity and the biology of cancer invasion and metastasis. Cancer Res 1978;38:2651-60.

76 Fidler IJ, Gersten DM, Hart IR. The biology of cancer invasion and metastasis. Adv Cancer Res 1978;28:149-250.

77 Brunson KW, Beattie G, Nicolson GL. Selective and altered properties of brain-colonizing metastatic melanoma. Nature 1978;272:543-5.

${ }^{78}$ Brunson KW, Nicolson GL. Selection of malignant variant cell lines for ovary colonization. J Supramol Struct 1979;11:517-28.

79 Tao T, Matter A. Vogel K, Burger MM. Liver colonizing melanoma cells selected from B16 melanoma. Int J Cancer 1979;28:854-7.

${ }^{80}$ Poste G, Doll J, Hart IR, Fidler IJ. In vitro selection of murine B16 melanoma variants with enhanced tissue-invasive 
properties. Cancer Res 1980;40:1636-44.

${ }^{81}$ Stackpole CW. Distant lung-colonizing and lung-metastasising populations in B16 mouse melanoma. Nature 1981;289: 798-800.

${ }^{82}$ Meyer JS, Bauer WC, Rao BR. Subpopulations of breast carcinoma defined by S-phase fraction, morphology and estrogen receptor content. Lab Invest 1978;38:225-35.

${ }^{83}$ Peterson SE, Bichel P, Lorentzen M. Flow-cytometric demonstration of tumour cell subpopulations with different DNA content in human colorectal carcinoma. Eur J Cancer 1978; 15:383-6.

${ }^{84}$ Fenger C, Bichel P. Flow-cytometric DNA analysis of anal canal epithelium and ano-rectal tumours. Acta Path Microbiol Scand $[A]$ 1982;89:351-5.

${ }^{85}$ Brattain MG, Fine WD, Khaled FM, Thompson J, Brattain DE. Heterogeneity of malignant cells from a human colonic carcinoma. Cancer Res 1981;41:1751-6.
86 Albino AP, Lloyd KO, Houghton AN, Oettgen HF, Old LJ. Heterogeneity in surface antigen and glycoprotein expression of cell lines derived from different melanoma metastases of the same patient. J Exp Med 1981;154:1764-78.

${ }^{87}$ Dear AS, Fabre JW. Demonstration with monoclonal antibodies of an unusual mononuclear cell infiltrate and loss of normal epithelial membrane antigen in human breast carcinomas. Lancet 1981;ii:434-8.

88 Wright DH. The identification and classification of nonHodgkin's lymphoma. Diagnostic Histopathology 1982;5: 73-111.

Requests for reprints to: Dr RL Carter, Haddow Laboratories, Royal Marsden Hospital and Institute of Cancer Research, Sutton, Surrey, England. 